\title{
EDITORIAL
}

\section{Hundred and fifty years of Plant Pathology in Sri Lanka}

Plant Pathology and Mycology have been two oldest scientific disciplines in Sri Lanka, continuing from colonial times. Plant Pathology emerged as a discipline in Sri Lanka (then Ceylon) 150 years ago, following the onset of the first plant disease of highly destructive nature of the country, as an epidemic in its prime cash crop.

The disease was the coffee rust which broke out in 1867 in a new coffee estate in Madulsima district (now Badulla district, Uva Province) and spread rapidly over the entire coffee growing districts in the region. Within 10 years, the disease had completely wiped out the hill country's flourishing coffee cultivation. The country had to face severe economic hardships during and after the period. The cause of the disease was later identified as the biotrophic fungus, Hemileia vastatrix. Numerous other Coffea species were introduced to replace rust-infected coffee, but none were resistant to the disease. Other diseases, especially the black rot caused by Corticium invisum, were also prevalent. These led to abandoning the cultivation of coffee in the highlands and the beginning of large-scale tea cultivation in Ceylon. The disease was alleged to have been spread from Ceylon to other countries in Africa and Tropical Asia but the evidence indicated that Hemileia was indigenous on native species of Coffea throughout Africa and the Eastern tropics.

The pioneering efforts by two British Scientists, Daniel Morris and Marshall Ward, to study coffee rust disease, though late, were highlights in the annals of Plant Pathology. This led to the birth of Plant Pathology in the country and opening of the first chapter on plant disease investigations laying foundation for Plant Pathology in the tropics.

\section{First 40 year in to the $20^{\text {th }}$ century}

The second phase in plant disease investigations followed the general pattern of development of Mycology in the country rather than of applied Plant Pathology as anticipated. Diseases in plantation crops like tea, rubber and cacao were quite a few in numbers at that time and not causing serious damage except for an occasional death of a tree due to root disease which did not warrant immediate control measures. Mycology started as a discipline in Ceylon during the latter parts of the $18^{\text {th }}$ century by British long before the coffee rust epidemic broke out. Emphasis of Mycology centered around descriptive studies and taxonomy of fungi which led to the identification of over 2,000 fungi, a majority being new species records to Ceylon. Through this process, 885 new fungal diseases affecting 340 host plants had been diagnosed by the year 1936, mainly due to the effort of Mycologists. During the period, theories were developed to explain the cause and development of disease and predisposition of plants to disease. Among other diseases widespread were cacao canker (Phytophthora sp.), banana bunchy top, first introduced in 1912 with plantain suckers from Australia, and powdery mildew (Oidium heveae) in 1925. "The Diseases of the Tea Bush" by T. Petch, was published in 1923 by Macmillan and Co. Ltd., London.

\section{After 1940s}

Applied Plant Pathology commenced in the country during the mid-twentieth century, focusing on agricultural and industrial crops. Field experimental analysis in epidemiological studies and disease control were introduced. A wilt-resistant brinjal variety was discovered and the feasibility of controlling the frog eye disease in tobacco by a systematic spray programme was demonstrated. A textbook titled "Diseases of Village Crops in Ceylon" by Malcolm Park and M. Fernando's was published in 1941.

The more dynamic phase in the development of Plant Pathology originated after the second world-war. The period marked the introduction of intensive standards of manuring and intensive cultivation of agricultural crops intended to maximize the yields and satisfy the consumer with a uniform produce. This also resulted in increased appearance of explosive epidemics and spread of disease. The first scaring disease prevailing was the blister blight, caused by Exobasidium vexans which was considered a grave threat to the tea industry. Pioneering work recommended protection of susceptible plants with copper fungicides, modification of agricultural practices and establishment of blister blight resistant clones as control measures. By 1950 spraying copper fungicides was shown to protect tea against the disease. The finding allowed tea cultivation in the mid- and upcountry and prevented an economic disaster similar to the collapse of coffee.

Meantime, the frequent appearance of viral diseases in cultivated crops, Swollen Shoot in cacao and Chilli Virus Complex was recognized and preventive measures were recommended. Potato cultivations were troubled by the bacterial wilt, late blight and viral disease. The challenge was to address these disease problems. A sudden decline of citrus trees appeared. An Australian Plant Pathologist, working in Ceylon, recognized similarity of the disease to "Quick decline" or "Tristeza", a dreaded virus disease of citrus prevalent in certain countries.

Blast and sheath blight disease were among the most troubling fungal diseases in rice. Blast control measures were based on development of resistant rice varieties by breeding which involved selection of resistant parental lines from among indigenous rice varieties and combining 
it with other desirable characters. Late Dr. Nissanka Seneviratne, Senior Plant Pathologist at the DOA, pioneered research that enabled the country to develop high yielding rice varieties, resistant to fungal and bacterial diseases. The farmers in rice cultivating districts hardly spent any money on fungicides and bactericides. Had the rice cultivation necessitated regular pesticide applications, environmental consequences would have been disastrous, quite apart from the enormous costs of importation of high-priced chemicals. The efforts of DOA rice researchers enabled continuing this research during the period after Dr. Seneviratne era.

The country has strengthened its vigilance on possible introduction of new diseases and new strains of existing pathogens. Scientific basis was laid for sensible plant import and quarantine regulations through the Plant Protection Ordinance of Ceylon 1924 (No. 10 of 1924). Country's vigilance was further strengthened by the adoption of Plant Quarantine Convention sponsored by FAO of the UN. Plant Quarantine activities became more efficient with the establishment of Plant Quarantine Centre at Katunayake with modern facilities. 'Diseases of cultivated plants, their Diagnosis and Treatment in Ceylon' by D.V.W. Abeygunawardena (1969) was a comprehensive guide to Plant Pathology, as a subject as well as to the diseases common in plants cultivated in Ceylon, which is useful even in today's context of Plant Pathology, 50 years after the book was written.

\section{0 onwards}

The first 100 years' practice of Plant Pathology in the country has seen the diagnosis of 1100 plant diseases affecting 431 plants. Looking back to the past fifty-years from today, over 150 new diseases have been added to this list. New diseases were regularly introduced with importation of crop plant material, food items and seed potatoes etc. The Plant Protection Ordinance 1924 was repealed by the Plant Protection Act, No. 35 of 1999. The new act has better provision against the introduction and spread of weeds, pests and diseases injurious or destructive to plants. The number of fungal and Oomycota pathogens, identified after 1950 , amounts to 230 species belonging to 110 genera from crop, forest and ornamental plants and freshly harvested produce in the country. Among them the most recorded were the Colletotrichum species. The genus has undergone intense molecular revision increasing the species in great numbers and attention as a plant pathogen worldwide. The highest number of fungi was recorded from vegetable diseases, followed by fruit and plantation crops, which added together, amount to $69 \%$ of the total number recorded. Powdery mildews are most common in many parts of the country, due to prevailing favorable weather conditions.

Teaching Plant Pathology, at undergraduate level, first commenced in local Universities in 1960's, often assisted by Visiting Plant Pathologists from Research Institutes. After 1980's, teaching Plant Pathology became a norm in most local Universities. This followed the beginning of research and postgraduate training. Colombo University pioneered postgraduate teaching with an M.Sc. in Plant Pathology and Peradeniya was among the next to follow. These were intensified with the establishment of Postgraduate Institutes affiliated to Universities since early 1980s, producing numerous Ph.D, M.Phil. and M.Sc. degrees.

While Agricultural and Plantation crop research institutes were focusing on diseases of crop plants designated to them, the Universities stepped up investigations into disease in forest, ornamental and horticultural plants and harvested fresh produce. In addition, research involving molecular and nano-technological tools in plant disease diagnosis and management got underway.

Disease management is an important part of Plant Pathology which has become more complex today than ever before with modern innovations in diagnostic and disease control options. Modern Plant Pathology presents a variety of PCR-based diagnostic tools and pathogen identification. Discovery of chemicals with new modes of action of low environmental impact, biological control agents with reliable and persistent activity, as well as the development of new plant varieties with durable disease resistance and also using constitutive and induced natural disease resistance offered multiple approaches for plant disease control. Safer chemicals with potential of induction of plant defense mechanisms started flooding the market. Modern science offers an array of strategies for enhancing disease resistance of crop plants in sustainable ways, with potential for reduced pesticide usage.

Increasing importance of Plant Pathology in the country demanded establishment of Sri Lanka Association for Mycology and Plant Pathology (SLAMPP) through collective efforts of Plant Pathologists and Mycologists, led by Prof. N. K. B. Adikaram, in 2007. By this time, the Plant Protection Society, founded in early 1990s by a group of Agriculturalists, including Prof J.M.R.S. Bandara, had ceased to be functional.

\section{Challenges today}

The country has a small but formidable group of Plant Pathologists with diverse individual specialties and interests, performing a vital role. One of the biggest challenges today is the implementation of crop protection practices for pests and diseases under the advancing climate changes. Trends of climate change are reflected by precipitation and temperature patterns which can make areas vulnerable to floods, droughts, changes in crop viability and new diseases. Changing agricultural environments would demand new disease control approaches as climate change might influence the incidence, prevalence and severity of plant diseases. Certain existing preventive measures such as adjustment of planting and sowing dates, use of diverse species in cropping systems and disease resistant or tolerant cultivars plus reliable disease forecasting tools, effective quarantine and application of Integrated Pest Management would prove useful for preventing future disease epidemics. Many developing countries have no access to science-based farming practices that can buffer agriculture from climate change. With climate change, countries need science more than ever. The potential of modern biology to search for new strategies based on chemical, genetical and 
biological control options is remarkably high. Stringent legislation that would prompt strict adherence to the guidelines regarding pesticide and agrochemical usage in the country must be brought in place. These would help relieve the country from decades-long pesticide poisoning of horticultural and agricultural fresh produce harvested for human consumption.

The National Symposium, "Plant Health 2019", was held on $30^{\text {th }}$ August 2019 at the Oak Ray Regency Hotel, Kandy with the theme of "Ensuring safer plant produce for human consumption". This was the first symposium of its kind to be held and only the second Plant Pathology Symposium ever to be held in the country's history. The symposium, that coincided with the United Nation declaration of the year 2020 as the "International year of Plant Health", was organized by the SLAMPP. The Special issue of the Ceylon Journal of Science is dedicated to the Proceedings of the National Symposium "Plant Health 2019”.

N.K.B. Adikaram

National Institute of Fundamental Studies Email:n.k.b.adikaram@gmail.com nimal.ad@nifs.ac.lk

\section{Bibliography}

Abeygunawardhana, D.V.W. (1966). A Century of Plant Disease investigations in Ceylon. Proceedings of Ceylon Association for the Advancement of Science, 14-17 December, Presidential Address, Section B, Agriculture and Forestry 111-126

Adikaram, N.K.B. and D.M.D. Yakandawala (2020). A Checklist of plant pathogenic fungi and Oomycota in Sri Lanka. Ceylon Journal of Science 49 (1): 93-123.

Petch, T. and Bisby, G.R. (1950). The fungi of Ceylon. Ceylon Government Press, Colombo, Ceylon, 111Pp.

Seneviratne, S.N. de S. and Jeyanandarajah, P. (2004). Rice diseases - problems and progress. Tropical Agricultural Research and Extension 7: 30-48. 